\title{
Bilateral median and ulnar neuropathy at the wrist in a parquet floorer
}

\author{
M dell'Omo, G Muzi, T A Cantisani, S Ercolani, M P Accattoli, G Abbritti
}

Institute of

Occupational

Medicine, University

of Perugia, Via E dal

Pozzo, 06100 Perugia,

Italy

$M$ dell'Omo

G Muzi

$S$ Ercolani

M P Accattoli

G Abbritti

Neurophysiopathology

Unit, Ospedale

"Silvestrini", 06100

Perugia, Italy

T A Cantisani

Correspondence to:

Dr Marco dell'Omo

Institute of Occupational

Medicine, University of

Pedigia, Via E dal Pozzo,

06100 Perugia, Italy.

Accepted 13 October 1994

\begin{abstract}
Many cases of work related compression neuropathy of the ulnar and median nerves at the wrist have been described. This report presents a case of bilateral distal neuropathy of the median and ulnar nerves in a parquet floorer, who laid wooden block flooring by hand and used the palms and volar surface of both hands to hit the blocks into place. He also used an electric sander and polisher. Bilateral numbness and paraesthesias in all fingers had been present for about one year. Clinical examination was normal; the neurological assessment indicated slight impairment in response to tactile, heat, and pain stimuli in all 10 fingers. Electroneurography showed increased distal motor latencies of median and ulnar nerves at both wrists, although the lower limbs were normal. The results of blood, urine, and instrumental tests excluded systemic disease or local factors that could cause compression neuropathy. After stopping work for three months, the clinical picture and electroneurographic results improved. These data support the hypothesis that the damage to the median and ulnar nerves had been caused by the patient's way of working, which provoked repeated bilateral microtrauma to his wrists. To diagnose work related multiple neuropathy can be difficult and an accurate work history is necessary. Preventive measures and diligent health care are required for this category of worker.
\end{abstract}

(Occup Environ Med 1995;52:211-213)

Keywords: carpal tunnel syndrome; ulnar nerve; occupational

Electrophysiological study of the median and ulnar nerves

\begin{tabular}{|c|c|c|c|c|}
\hline \multirow[b]{2}{*}{ Nerve } & \multirow{2}{*}{$\begin{array}{l}\text { Stimulation } \\
\text { site }\end{array}$} & \multirow{2}{*}{$\begin{array}{l}\text { Registration } \\
\text { site (muscle) }\end{array}$} & \multicolumn{2}{|l|}{ Distal latency } \\
\hline & & & May 1993 (ms) & Aug 1993 (ms) \\
\hline \multirow[t]{2}{*}{$\mathbf{R}$ median } & Wrist & Opponens pollicis & $11 \cdot 0$ & $8 \cdot 4$ \\
\hline & Elbow & Flexor carpi radialis & $3 \cdot 0$ & \\
\hline \multirow[t]{2}{*}{ R ulnar } & Wrist & Abductor digiti minimi & $2 \cdot 8$ & $2 \cdot 5$ \\
\hline & Wrist & Adductor pollicis & $13 \cdot 0$ & $6 \cdot 6$ \\
\hline L median & Wrist & Opponens pollicis & $10 \cdot 4$ & $5 \cdot 5$ \\
\hline \multirow{2}{*}{ L ulnar } & $\begin{array}{l}\text { Elbow } \\
\text { Wrist }\end{array}$ & $\begin{array}{l}\text { Flexor carpi radialis } \\
\text { Abductor digiti minimi }\end{array}$ & $\begin{array}{l}3 \cdot 4 \\
4 \cdot 6\end{array}$ & 5.5 \\
\hline & Wrist & Adductor pollicis & $18 \cdot 0$ & $9 \cdot 8$ \\
\hline
\end{tabular}

$\mathrm{R}=$ right; $\mathrm{L}=$ left.

The most common entrapment neuropathy ${ }^{1}$ in the upper limbs is due to compression of the median nerve at the wrist, which causes the so called carpal tunnel syndrome (CTS). ${ }^{12}$ Compression syndromes of the ulnar nerve at or below the wrist have also been well documented. ${ }^{13}$

Although occupational hazards may play a part in the aetiopathogenesis of these syndromes, they often pass unrecognised. ${ }^{2}$

This case report of compression neuropathy in the upper limbs is unusual because of the bilateral involvement of the median and ulnar nerves. The patient was a parquet floorer, an occupation that is not included among those at risk of CTS and distal neuropathy of the ulnar nerve.

\section{Case report}

A 43 year old man was referred to the Department of Occupational Medicine, University of Perugia, Italy, because numbness and paraesthesias had been present in all fingers of both hands for about one year. No other symptoms were present. A floorer for about 25 years, the patient was mainly occupied in hand laying parquet flooring. At work he used different glues and had the habit of pressing each wooden block into position with the base of the palm and the volar surface of both wrists. For about 80 hours every month, he also used a heavy electric floor sander and polisher that produced vibrations. The patient presented no case history of neurological, endocrine or metabolic disease, no current connective tissue disease, or previous wrist and hand trauma.

A neurological examination showed slight impairments in response to tactile, heat, and pain stimuli in all 10 fingers. Muscular strength was normal in both hands. Phalen's and Tinel's signs were absent.

Electroneuromyography explored the opponens pollicis, adductor pollicis, abductor digiti minimi, flexor carpi radialis, brachioradialis, and pedidius muscles, and the median, ulnar, radial, and peroneal nerves. No spontaneous activity potentials were evident in any muscle and voluntary activity produced an interference type trace with normal motor unit potentials. Median and ulnar nerves (table) showed considerable bilateral increases in distal motor latency at the wrists. Motor conduction velocity in the radial and peroneal nerves was normal.

Standard radiological studies of hands, wrists, elbows, and shoulders were normal. 
Magnetic resonance (MR) imaging showed no morphological abnormalities in the wrists.

Electrocardiography, chest radiographs, routine blood tests, erythrocyte sedimentation rate, glycaemia, urine analysis, rheumatoid factor tests, thyroid hormone, and thyrotropin concentrations were all normal.

We suspected that the patient's job may have been associated with the syndrome, so we advised him to suspend his activity. Three months later, he reported a significant improvement in the paraesthesia in the fourth and fifth fingers of both hands. Electroneurography showed distal motor latencies were significantly improved bilaterally (table) in both the ulnar and median nerves.

\section{Discussion}

At the wrist the median nerve passes through the carpal tunnel and the ulnar nerve through Guyon's canal. The carpal tunnel is bounded by the carpal bones and is roofed by the transverse carpal ligament. Guyon's canal, which is medial to the carpal tunnel, is bounded posteriorly by the transverse carpal ligament, anteriorly by the volar carpal ligament and by the flexor carpi ulnaris tendon, medially and proximally by the pisiform bone and laterally and distally by the hook of hemate. In these two canals, a reduction in volume and an increase in internal pressure may cause entrapment neuropathy. ${ }^{1}$ The ulnar nerve may also be damaged distally, after its exit from Guyon's canal. ${ }^{3}$

In this case, paraesthesia affected all 10 fingers, which suggests simultaneous bilateral involvement of the ulnar and median nerves. Phalen's and Tinel's signs were absent, but a bilateral CTS could not be excluded as neither sign has a high diagnostic validity. ${ }^{4}$

The neurophysiological investigation confirmed severe bilateral distal impairments in the median and ulnar nerves that caused a notable increase in motor latencies. The site of median nerve lesion was most probably the carpal tunnel. To identify the site of the ulnar nerve lesion was more difficult because of the anatomical complexities and differences in the distal tract between people. Inside Guyon's canal the ulnar nerve divides into the superficial and deep motor branches. The superficial branch is predominantly sensory and extends to the ulnar surface of the hypotenar eminence, the fourth and fifth fingers, whereas the deep branch supplies the hypothenar muscles (abductor, opponens, and flexor brevis digiti minimi). The deep motor branch curves, then reaches the palm and innervates the interossei, the third and fourth lumbricals, and the adductor pollicis muscles. Electroneurography of the ulnar nerves showed a significant increase in distal latency in the adductor pollicis muscle. When the electrode was placed in the abductor digiti minimi, latency in the left arm was lengthened but latency in the right was within the upper normal limit.

The symptoms reported by the patient were indicative of involvement of the superficial sensory branch. The notable increase in distal latency in the adductor pollicis muscle compared with levels in the abductor digiti minimi indicated damage to the deep motor branches in the palm of the hands after the muscles of the hypotenar eminence had been supplied. The data suggested also demyelinisation of the ulnar nerves inside Guyon's canal.

Many systemic diseases and local factors can determine the onset or worsening of the CTS or Guyon canal syndrome. ${ }^{1}$ In this patient, the case history, clinical, and laboratory findings excluded any endocrine or metabolic pathology that could be linked to compression neuropathy. Magnetic resonance imaging is a useful aid to diagnosis; it provides a well defined picture of the bones and soft tissues of the hand and wrist, ${ }^{5}$ but in our patient it did not show any anatomical alteration in the carpal tunnels or Guyon's canals.

Both the CTS and neuropathies of the distal ulnar nerve may be work related. Increased risk of CTS has been documented in grocery checkers, packers, electronics assembly workers, butchers, and garment workers, 267 whereas neuropathy of the ulnar nerve has been found in workers who use hand tools, cyclists, musicians, video game players, and computer operators. ${ }^{168} \mathrm{We}$ have found no report of neuropathy due to compression of the ulnar and median nerves in a parquet floorer. The CTS may also be associated with neuropathy of the ulnar nerve at the wrist $^{9}$ and may be bilateral in some categories of workers. ${ }^{10}$ Such a severe, bilateral involvement of the median and ulnar nerves is unusual.

The aetiological agent was, in our view, repeated wrist and palm trauma. When at work, after having glued and laid the wood blocks, the floorer used the right wrist and palm to hit and press them into place in one direction and then the left wrist and palm to position them in the other. Hands were held in dorsal flexion, which increases pressure inside the semirigid carpal tunnel, ${ }^{11}$ and probably contributed to the genesis of lesions. Another pathogenic factor could have been the vibrations to which the floorer was exposed when using the electric floor sander and polisher. Experimental data indicated that vibrations cause perineural oedema, which may, if the vibratory stimulus persists over time, become chronic and lead to the formation of fibrous tissue. ${ }^{12}$ The consequent increased pressure in the carpal tunnel and Guyon's canal could damage the nerves that pass through them.

The main difficulty in the differential diagnosis was that the floorer was exposed to glues some of which contained n-hexane, a neurotoxic solvent. Unlike in our patient, $n$-hexane neuropathy first affects the lower limbs and then evolves from the distal to the proximal end of the nerve. Nerve conduction velocity remains normal for a long period of time while the early signs are a reduction in 
amplitude of the motor potential and the electromyographic evidence of denervation (fibrillation and fasciculation potentials). ${ }^{13}$

In conclusion, as there was no evidence of anatomical alterations in the carpal tunnel or Guyon's canal, of systemic disease, or polyneuropathy, the hypothesis that bilateral damage to the median and ulnar nerves was caused by repeated trauma to the palm and wrist seems feasible. The trauma can be linked to the patient's way of working and to his use of a vibratory tool. Evidence in support of the hypothesis includes better electroneurographic findings and a considerable clinical improvement after he had stopped working for three months.

This case report shows that although many occupations may contribute to the genesis of compression neuropathies in the upper limbs, the clinical signs are not always the same and different ways of carrying out tasks make identifying the aetiopathogenic agent or factor difficult. Therefore diligent health care is needed for workers who perform repetitive tasks that involve the upper limbs so that any peripheral neuropathy or other pathology of the muscles, tendons, and joints is diagnosed in the early stages. Epidemiological studies are also needed to assess the prevalence of compression neuropathies in little known categories of workers such as floorers.
We acknowledge the assistance of $\operatorname{Dr} G \mathrm{~A}$ Boyd in the preparation of this manuscript.

1 Stewart JD. Compression and entrapment neuropathies. In: Dick PJ, Thomas PK, eds. Peripheral neuropathy. In: Dick PJ, Thomas PK, eds. Peripheral

2 Baker EL, Ehrenberg RL. Preventing the work-related carpal tunnel syndrome: physician reporting and diagnostic criteria. Ann Intern Med 1990;112:317-9.

3 Shea JD, McClain EJ. Ulnar nerve compression syndromes at and below the wrist. $\mathcal{F}$ Bone foint Surg Am 1969;51:1095-103.

4 De Krom MCTFM, Kester ADM, Knipschild PG, Spaan F. Efficacy of provocative tests for diagnosis of carpal tunnel syndrome. Lancet 1990;335:393-5.

5 Weiss KL, Beltran J, Shamam OM, Stilla RF, Levey M High-field MR surface-coil imaging of the hand and wrist. Part I. Normal anatomy. Radiology 1986;160: 143-6.

6 Feldman RG, Goldman R, Keyserling WM. Peripheral nerve entrapment syndromes and ergonomic factors. $A m$ f Ind Med 1983;4:661-81.

7 Hagberg M, Morgenstern H, Kelsh M. Impact of occupations and job tasks on the prevalence of carpal tunnel syndrome. Scand $f$ Work Environ Health 1992;18: 337-45.

8 Davie C, Katifi H, Ridley A, Swash M. "Mouse-trap" or personal computer palsy. Lancet 1991;338:832.

9 Buchthal F, Rosenfalk A, Trojaborg W. Electrophysiological findings in entrapment of the median nerve a wrist and elbow. $\mathcal{f}$ Neurol Neurosurg Psychiatry 1974 37:340-60.

10 Falck B, Aarnio P. Left-sided carpal tunnel syndrome in butchers. Scand f Work Environ Health 1983;9:291-7.

11 Gelberman RH, Hergenroeder PT, Hargens AR Lundborg GN, Akeson WH. The carpal tunnel syndrome. A study of carpal canal pressures. $\mathfrak{f}$ Bone foint Surg Am 1981;63:380-3.

12 Lundborg G, Dahlin LB, Danielsen N, Hansson HA, Necking LE, Pyykko I. Intraneural edema following exposure to vibration. Scand $₹$ Work Environ Health exposure to vib

13 Abbritti G, Siracusa A, Cianchetti C, Coli CA, Curradi F, Perticoni GF, De Rosa F. Shoe-makers' polyneuropathy in Italy: the aetiological problem. Br $\mathcal{F}$ Ind Med 1976; 33:92-9. 